\title{
U.S. Spacesuit Knowledge Capture Status and Initiatives
}

\author{
Cinda Chullen ${ }^{1}$ and Ron Woods ${ }^{2}$ \\ NASA, 2101 NASA Parkway, Houston, Texas, 77058, USA \\ Juniper Jairala ${ }^{3}$ and Rose Bitterly ${ }^{4}$ \\ Engineering and Science Contract Group, Jacobs Engineering Technology, Houston, Texas, 77058, USA \\ Joe McMann ${ }^{5}$ \\ Olde Irish Consulting, Temple, Texas, 76502, USA \\ and \\ Cathleen Lewis ${ }^{6}$ \\ National Air and Space Museum, Washington, DC 20560, USA
}

The National Aeronautics and Space Administration (NASA), other organizations and individuals have been performing United States (U.S.) spacesuit knowledge capture since the beginning of space exploration via publication of reports, conference presentations, specialized seminars, and classes instructed by veterans in the field. Recently, the effort has been more concentrated and formalized whereby a new avenue of spacesuit knowledge capture has been added to the archives through which videotaping occurs, engaging both current and retired specialists in the field presenting technical scope specifically for education and preservation of knowledge or being interviewed to archive their significance to NASA's history. Now with video archiving, all these avenues of learning are brought to life with the real experts presenting their wealth of knowledge on screen for future learners to enjoy. U.S. spacesuit knowledge capture topics have included lessons learned in spacesuit technology, experience from the Gemini, Apollo, Skylab and Shuttle programs, hardware certification, design, development and other program components, spacesuit evolution and experience, failure analysis and resolution, aspects of program management, and personal interviews. These archives of actual spacesuit legacy now reflect its rich history and will provide a wealth of knowledge which will greatly enhance the chances for the success of future and more ambitious spacesuit system programs. In this paper, NASA's formal spacesuit knowledge capture efforts will be reviewed and a status will be provided to reveal initiatives and accomplishments since the inception of the more formal U.S. spacesuit knowledge program. A detail itemization of the actual archives will be addressed along with topics that are now available to the general NASA community and the public. Additionally, the latest developments in the archival relationship with the Smithsonian will be discussed.

\footnotetext{
${ }^{1}$ Project Engineer, Space Suit and Crew Survival Systems Branch, Crew and Thermal Systems Division, NASA Parkway, Houston, TX 77058/EC5.

${ }^{2}$ Project Engineer, Space Suit and Crew Survival Systems Branch, Crew and Thermal Systems Division, NASA Parkway, Houston, TX 77058/EC5.

${ }^{3}$ Project/Test Engineer, Hardware Systems Project Engineering, 2224 Bay Area Blvd, Houston, TX 77058/JE2-B1N,

${ }^{4}$ Admin Specialist, Hardware Systems Project Engineering, 2224 Bay Area Blvd, Houston, TX 77058/JE2-B1N.

${ }^{5}$ Sole Proprietor, Olde Irish Consulting, 4858 Lakeaire Circle, Temple, Texas, 76502.

${ }^{6}$ Museum Curator, Smithsonian Institution, National Air and Space Museum, Space History Division, P.O. box 37012, Washington, DC 20013-7012/MRC 311.
} 